Article

\title{
Depopulation of Caged Layer Hens with a Compressed Air Foam System
}

\author{
Shailesh Gurung ${ }^{1}$, John Hoffman ${ }^{1}$, Kendre Stringfellow ${ }^{1}$, Daad Abi-Ghanem ${ }^{1}$, Dan Zhao ${ }^{1}$, \\ David Caldwell 1, Jason Lee ${ }^{1}$, Darrel Styles ${ }^{2}$, Luc Berghman ${ }^{1}$, James Byrd ${ }^{3}$, Yuhua Farnell ${ }^{1}$, \\ Gregory Archer ${ }^{1}$ and Morgan Farnell ${ }^{1, *}$ \\ 1 Department of Poultry Science, Texas A\&M AgriLife Research and Extension, \\ College Station, TX 77843, USA; sg45902@tamu.edu (S.G.); john.hoffman@cobb-vantress.com (J.H.); \\ kendre.stringfellow@abvista.com (K.S.); daad.abighanem@gmail.com (D.A.-G.); dz137@tamu.edu (D.Z.); \\ caldwell@tamu.edu (D.C.); jtlee@tamu.edu (J.L.); berghman@poultry.tamu.edu (L.B.); \\ yfarnell@tamu.edu (Y.F.); garcher@tamu.edu (G.A.) \\ 2 Veterinary Services, Animal and Plant Health Inspection Service- US Department of Agriculture, \\ Riverdale Park, MD 20737, USA; darrel.k.styles@aphis.usda.gov \\ 3 Southern Plains Agricultural Research Center, Agricultural Research Service, US Department of Agriculture, \\ College Station, TX 77843, USA; byrdmen8@yahoo.com \\ * Correspondence: mfarnell@tamu.edu; Tel.:+1-979-847-7363
}

Received: 7 November 2017; Accepted: 8 January 2018; Published: 11 January 2018

Simple Summary: Reportable diseases, such as avian influenza, spread rapidly among poultry, resulting in the death of a large number of birds. Once such a disease has been diagnosed at a farm, infected and susceptible birds are rapidly killed to prevent the spread of the disease. The methods to eliminate infected caged laying hens are limited. An experiment was conducted to study the effectiveness of foam made from compressed air, water, and soap to kill laying hens in cages. The study found that stress levels of the hens killed using compressed air foam in cages to be similar to the hens killed by carbon dioxide or the negative control. Hens exposed to carbon dioxide died earlier as compared to the foam methods. The authors conclude that application of compressed air foam in cages is an alternative to methods such as gas inhalation and ventilation shutdown to rapidly and humanely kill laying hens during epidemics.

Abstract: During the 2014-2015 US highly pathogenic avian influenza (HPAI) outbreak, 50.4 million commercial layers and turkeys were affected, resulting in economic losses of $\$ 3.3$ billion. Rapid depopulation of infected poultry is vital to contain and eradicate reportable diseases like HPAI. The hypothesis of the experiment was that a compressed air foam (CAF) system may be used as an alternative to carbon dioxide $\left(\mathrm{CO}_{2}\right)$ inhalation for depopulating caged layer hens. The objective of this study was to evaluate corticosterone (CORT) and time to cessation of movement (COM) of hens subjected to $\mathrm{CAF}, \mathrm{CO}_{2}$ inhalation, and negative control (NEG) treatments. In Experiment 1, two independent trials were conducted using young and spent hens. Experiment 1 consisted of five treatments: NEG, $\mathrm{CO}_{2}$ added to a chamber, a $\mathrm{CO}_{2}$ pre-charged chamber, $\mathrm{CAF}$ in cages, and $\mathrm{CAF}$ in a chamber. In Experiment 2, only spent hens were randomly assigned to three treatments: CAF in cages, $\mathrm{CO}_{2}$ added to a chamber, and aspirated foam. Serum CORT levels of young hens were not significantly different among the CAF in cages, $\mathrm{CAF}$ in a chamber, NEG control, and $\mathrm{CO}_{2}$ inhalation treatments. However, spent hens subjected to the CAF in a chamber had significantly higher CORT levels than birds in the rest of the treatments. Times to COM of spent hens subjected to CAF in cages and aspirated foam were significantly greater than of birds exposed to the $\mathrm{CO}_{2}$ in a chamber treatment. These data suggest that applying CAF in cages is a viable alternative for layer hen depopulation during a reportable disease outbreak.

Keywords: HPAI; depopulation; compressed air foam; caged layers 


\section{Introduction}

The US poultry industry has faced disease outbreaks and natural disasters that require flocks to be destroyed. Natural disasters such as hurricanes and floods cause damage to poultry houses, feed mills, roads, and power lines leading to emergency killing of flocks to prevent further suffering [1]. Reportable poultry diseases such as highly pathogenic avian influenza (HPAI), exotic Newcastle disease (END), avian infectious laryngotracheitis, avian infectious bronchitis, and mycoplasmosis are also threats to the poultry industry [2]. The last reported US END outbreak was in 2002-2003 in California, which resulted in the loss of 3.16 million birds and \$161 million [3]. Most recently, the US poultry industry lost 43 million layer and pullet hens and 7.4 million turkeys during the 2014-2015 HPAI outbreak [4]. The layers and turkeys lost alone were worth $\$ 1.6$ billion, and the overall economic losses were estimated to be $\$ 3.3$ billion $[5,6]$.

Euthanasia is the act of terminating the life of an animal in a way that involves minimum pain and distress [7]. Euthanasia, meaning a good death, is distinct from depopulation. On the other hand, depopulation is an emergency measure used to rapidly kill animals with as much consideration given to their welfare as possible [7,8]. Elimination of poultry infected or at risk of infection from HPAI is a primary US animal health policy to control and eradicate the virus [9]. Therefore, birds within a three kilometer radius of an infected zone are killed and disposed of [10]. Methods used for mass depopulation of poultry depend upon the species, housing type, age of bird, ambient temperature, and available carcass disposal methods [1].

The American Veterinary Medical Association (AVMA) has approved carbon dioxide $\left(\mathrm{CO}_{2}\right)$ inhalation as a means of euthanizing poultry [7]. Carbon dioxide is an analgesic and anesthetic gas $[11,12]$. Exposure to $\mathrm{CO}_{2}$ inhalation induces hypercapnic hypoxia in birds, which results in rapid unconsciousness and ultimately leads to death [13]. However, mammals and birds may show aversive responses to $\mathrm{CO}_{2}$ inhalation [14]. Humans exposed to $\mathrm{CO}_{2}$ concentrations between $40 \%$ and $55 \%$ experienced painful sensations [15] due to acidification of respiratory mucosa upon exposure to $\mathrm{CO}_{2}$ [16]. Birds experience respiratory distress such as gasping (breathlessness) and deep breathing while remaining conscious [17]. Birds exposed to liquid $\mathrm{CO}_{2}$ may also suffer from cold stress [18]. The use of $\mathrm{CO}_{2}$ inhalation may not be suitable for some types of poultry houses due to differences in construction. The method requires effective sealing of poultry houses, special equipment, and the rapid flow of a large volume of gas over the birds [1,17]. Application of $\mathrm{CO}_{2}$ also presents a safety risk to human personnel involved [17].

Water-based foam is a suitable depopulation alternative to $\mathrm{CO}_{2}$ inhalation of floor reared poultry [8]. The USDA Animal and Plant Health Inspection Service (APHIS) and the AVMA have accepted the use of water-based foam for killing commercial broilers and turkeys (poultry that are not housed in cages) [8]. Aspirated foam nozzles and high-expansion foam generator systems produce the water-based foam used for floor-reared poultry $[19,20]$. The USDA-APHIS performance standard recommends the bubble size of the water-based foam to be $1.58 \mathrm{~cm}(0.625$ inches $)$ or less. The water content of the foam should be enough that allows it to flow around the structures and at the same time cover the birds on the floor [8]. Foam is a collection of air-filled bubbles derived from a solution of detergents and water [21]. Foam has been widely used by firefighting departments for extinguishing fires [22,23]. Water-based foam depopulation was developed in response to the 2004 Delmarva avian influenza (AI) event [1]. Broilers and turkeys are immersed in foam which blocks the respiratory tract resulting in hypoxia, leading to loss of consciousness, convulsions, cerebral death, and cessation of cardiac activity [24]. However, depopulation of caged layer hens poses a different challenge. Foam developed for floor-reared poultry is a wet foam that drains quickly through mesh cage floors, making it unfit for caged layer houses. Furthermore, commercial cage farms have high stocking densities (100,000 or more layers per house) and are multi-tier buildings (5-10 tiers of cages), which 
limit access to conventional foaming methods [25]. The outbreak of a disease, like AI, in a caged layer facility would be the worst-case scenario, as a large number of birds would have to be depopulated rapidly, safely, and as humanely as possible.

The methods used for mass depopulation should be efficient and give due consideration to personnel safety and bird welfare. Birds subjected to euthanasia and depopulation methods are likely to suffer stress until they lose consciousness. It is vital for a depopulation method to result in a quick death to minimize suffering and contain the virus. Birds undergo clonic and tonic convulsions upon loss of consciousness during euthanasia [26,27]. Termination of such neuromuscular spasms (or cessation of movement) is an indicator of brain death [28]. Birds engulfed by foam cannot be visually evaluated for behavioral changes such as loss of posture or onset and cessation of convulsions. Accelerometers are sensors that measure changes in velocity due to movement [29]. Dawson and colleagues $[27,30]$ determined time to cessation of movement of broilers subjected to water-based foam depopulation based on their accelerometer data. Physiological responses of birds to stress are mediated by the limbic hypothalamo-pituitary-adrenocortical (HPA) axis and sympathetic-adrenalmedullary (SAM) axis [31]. The effects of HPA axis are mediated by release of glucocorticoids, like corticosterone, in response to stress $[32,33]$. Serum corticosterone is a common physiological parameter used to assess welfare in birds [34-37].

Aspirated and high expansion foams, used to depopulate floor reared poultry, are made by utilizing the kinetic energy from the flow of water. On the other hand, a compressed air foam (CAF) system uses energy from compressed air. Expansion ratio is a foam quality parameter. It is defined as the ratio of volume of finished foam to volume of aqueous foam solution [38]. Foam is classified into three kinds: low, medium, and high expansion foam with expansion ratios less than 20:1, 20:1 to 200:1, and more than 200:1, respectively [39]. Aspirated foam has a medium expansion ratio, while compressed air foam ranges from low to medium expansion. Since a CAF system is a closed system, foam concentrate, water, and air can be manipulated as required to produce finished foam. Benson and colleagues [1] were first to report the application of CAF for depopulation of broilers. A CAF system consists of a centrifugal water pump, a foam concentrate proportioner, an air compressor, and a mixing chamber [21,40]. In a CAF system, compressed air agitates a foam solution in a mixing chamber to produce a finished foam [40]. The ratio of aqueous foam solution and compressed air can be adjusted in a CAF system to produce a drier or wetter foam [23,41]. Ideal foam for cage operations (conventional, colony, or enriched colony) would be one that has a longer dewatering time and a small bubble size, since such foam would persist long enough in cages depriving birds of oxygen ultimately leading to death from hypoxia due to occlusion of the trachea. Compressed air foam has a uniform bubble size and better stability than air-aspirated foams [23].

The hypothesis of the experiment was that a compressed air foam system is a rapid and humane means for caged layer hen depopulation. The specific objectives of this study were to determine and compare serum corticosterone levels and time to cessation of movement of birds subjected to CAF, $\mathrm{CO}_{2}$ inhalation, and negative control treatments. Hens subjected to $\mathrm{CAF}$ and $\mathrm{CO}_{2}$ treatments were necropsied to evaluate signs of trauma or presence of foam in the respiratory tract.

\section{Materials and Methods}

\subsection{Experimental Animals}

Lohmann LSL young and spent hens were obtained from an egg integrator and housed in the Texas A\&M University Poultry Science Research, Teaching, and Extension Center layer barn prior to the experiments. The young hens were 20 weeks of age while the spent hens were 76-95 weeks old. All birds were cared for under an approved TAMU Institutional Animal Care and Use Committee (IACUC) protocol \# 2009-222. 


\subsection{Experiments}

Based on the objectives of the study, two separate experiments were carried out. The objective of Experiment 1 was to evaluate corticosterone (CORT) levels, while that of Experiment 2 was to determine time to cessation of movement (COM). Young and spent hens, separately, were the test subjects in Experiment 1, while only spent hens were used in Experiment 2. Birds in Experiment 1 were subjected to five treatments: negative control (NEG), $\mathrm{CO}_{2}$ added to a chamber after bird placement, pre-charged $\mathrm{CO}_{2}$ chamber, $\mathrm{CAF}$ in cages, and $\mathrm{CAF}$ in a chamber. Treatments were performed on two replicate days for each age group for a total of four replications for Experiment 1 . Twelve $(N=6$ and 6$)$ young hens and $13(N=6$ and 7$)$ spent hens were subjected to each of the five treatments. Experiment 2 consisted of three treatments: $\mathrm{CO}_{2}$ added to a chamber, CAF in cages, and aspirated foam in a floor pen on the same day. The number of spent hens randomly assigned to each of the three treatments in Experiment 2 was 16. The concentration of $\mathrm{CO}_{2}$ in both experiments was $100 \%$. A $208 \mathrm{~L}$ plastic chamber with a floor area of $3561 \mathrm{~cm}^{2}$ and height of $84 \mathrm{~cm}$ was used for application of treatments in both experiments. The hens in the NEG treatment were placed in cages and briefly restrained for jugular venipuncture. Compressed air foam was applied in the CAF in cages and CAF in a chamber treatments. The dimensions of each A-frame pullet cage was $0.61 \mathrm{~m} \times 0.57 \mathrm{~m} \times 0.38 \mathrm{~m}$. Three to four hens were placed at a time in each chamber and cage prior to treatments. In Experiment 2, a group of 16 hens allocated to the aspirated foam treatment were placed in a floor pen of the dimensions of $2.44 \mathrm{~m} \times 2.44 \mathrm{~m}$ The conventional cages used in the CAF in cages treatment, in Experiments 1 and 2, were positioned $0.1524 \mathrm{~m}$ above a plywood platform to simulate a layer house manure belt. Compressed gas tanks of $100 \% \mathrm{CO}_{2}$ were purchased from a local supplier. The flow rate of the gas for the $\mathrm{CO}_{2}$ added to a chamber treatment was set at $62 \mathrm{~L}$ per minute to achieve a gas displacement rate of $30 \%$ of the chamber volume in a minute. The chamber was filled for three minutes after hens were placed inside it. The same flow rate and time period was followed in the pre-charged $\mathrm{CO}_{2}$ chamber treatment. The hens were placed inside the chamber after the end of three minutes. However, gas concentration was not measured in the chamber.

\subsection{Foam Production}

The CAF unit (Rowe CAF LLC, Hope, AR, USA) consisted of a 1982 L per minute rotary screw air compressor (Vanair Inc., Michigan City, IN, USA), a 40.55 metric horsepower gasoline engine (Kohler Co., Kohler, WI, USA), a 567 L per minute centrifugal water pump (Hale Products, Inc., Ocala, FL, USA), and a foam concentrate proportioner ( $0.1 \%-10 \%$; FoamPro, Kingston, NY, USA). Water for the CAF was supplied from a $1135.6 \mathrm{~L}$ tank. A $37.9 \mathrm{~L}$ foam cell contained the foam concentrate necessary for the experiment. A Class A foam concentrate (ICL Performance Products, Rancho Cucamonga, CA, USA) was used at $3.5 \%$ in the CAF and $1 \%$ in the aspirated foam. Foam concentrate was injected by the proportioner into the water manifold of the CAF unit. A separate air manifold supplied compressed air to the mixing chamber. These three constituents of foam were agitated in the mixing chamber of the CAF unit. The flow rates of air and water into the mixing chamber were adjusted to produce a foam of the desired consistency and thickness. The final foam had consistency of that of a shaving cream (on visual inspection). Flow rate of aqueous foam solution and volume of compressed air are key to producing finished foam of desired nature. The compressed air foam produced was thick enough to stay in the cage for $5 \mathrm{~min}$ or longer and had a mean expansion ratio of 111:1. The finished CAF was released from a single $3.8 \mathrm{~cm}$ CAF unit through a $15 \mathrm{~m}$ long and $3.8 \mathrm{~cm}$ internal diameter firefighting hose attached to a $6.4 \mathrm{~cm}$ wide and $6 \mathrm{~m}$ long suction hose. This significantly reduced the velocity of the finished foam minimizing the impact on the hens. The foam stream was initially directed at the floor of the cage or chamber in consideration for the birds' welfare. The flow rate of CAF produced during this study was $1874 \mathrm{~L}$ per minute. Foam was applied to the cage for two minutes or filled the chamber within one minute. In Experiment 2, an aspirated nozzle (Spumifer American Company, Ridgefield Park, NJ, USA) was used to produce aspirated foam, a method conditionally approved for depopulation of floor-reared broilers and turkeys. The aspirated foam system had a flow rate of an 
estimated 11,356 L per minute. Environmental factors such as temperature and humidity may affect foam quality. However, all five treatments were performed on the same day, at the same location, with the same settings and same equipment, within an enclosed poultry barn.

\subsection{Experiment 1}

Serum CORT levels of young and spent hens were evaluated separately. A total of 65 spent hens and 60 young hens were used. The hens were subjected to foam, $\mathrm{CO}_{2}$, and $\mathrm{NEG}$ control for four minutes, after which they were removed. Death was ascertained by observing corneal and pedal reflexes of the birds. Blood samples were collected immediately (within $2 \mathrm{~min}$ ) by severing the femoral artery of hens in all treatments except the NEG control. The birds in the NEG control group were alive until venipuncture of the jugular vein for blood collection. These birds were euthanized afterward by cervical dislocation. Blood was allowed to clot for $1 \mathrm{~h}$ at room temperature and transported on ice to the laboratory. The blood was stored at $4{ }^{\circ} \mathrm{C}$ for $24 \mathrm{~h}$. Serum was collected by centrifuging blood at $1000 \times g$ for $15 \mathrm{~min}$. Serum corticosterone was evaluated by competitive ELISA kit ADI-901-097 (ENZO Life Sciences, Farmingdale, NY, USA) according to the instructions from the manual. Samples were run in duplicate. Absorbance was measured for each sample using a plate reader at $405 \mathrm{~nm}$ (BioTek Instruments Inc., Winooski, VT, USA). A four-parameter logistic regression model was used for curve fitting to interpolate the CORT levels from absorbance readings for each individual experimental subject. Intra-assay and inter-assay variability were $2.8 \%$ and $7.2 \%$, respectively.

\subsection{Experiment 2}

The experiment was conducted to determine time to cessation of movement of laying hens subjected to each depopulation treatment. Accelerometer data loggers (HOBO Pendant G, Onset Computer Corporation, Bourne, MA, USA) were attached to the shanks of each bird by zip ties to measure changes in the movement as hens were exposed to the treatments. The accelerometers were programmed to start logging data every second. The end point of convulsive movements was determined as the point where a flat line (no signal) was recorded. The time-interval between start of treatment until loss of motion was determined for each hen. Forty-eight spent hens were used in total in this trial.

\subsection{Postmortem Examination}

Gross necropsy was performed on hens subjected to foam or $\mathrm{CO}_{2}$ treatments in Experiment 1. Respiratory tracts were visually evaluated for signs of physical injury or presence of foam.

\subsection{Statistical Analysis}

In Experiment 1, samples with concentrations outside the range of the standard curve were removed from the study. Therefore in the case of pullet hens, four samples were removed from the $\mathrm{CO}_{2}$ in cage group and one sample was omitted from the NEG control group. In the case of spent hens, one sample from the CAF in a chamber group was removed. Except for the CAF in a chamber group, which had 12 samples, each of the remaining four treatments had 13 samples. Statistical analyses were performed on CORT values of serum samples from a total of 55 young and 64 spent hens. Tests for Normality (Shapiro-Wilk) and Levene's test for homogeneity of variance were performed on CORT and COM data using the PROC Univariate and PROC ANOVA procedures, respectively. Statistical analyses of CORT and time to COM data were done by one-way ANOVA using the PROC ANOVA procedure (SAS 9.4, Cary, NC, USA). Means deemed significant were further evaluated using Fisher's LSD post-hoc test. The tests were carried out at the $5 \%$ level of significance $(\alpha=0.05)$. 


\section{Results and Discussion}

\subsection{Weather Conditions}

In Experiment 1, the temperature and relative humidity, during the young hen study, were $18.9^{\circ} \mathrm{C}$ and $89 \%$ on the first replicate day and $25{ }^{\circ} \mathrm{C}$ and $83 \%$ on the second replicate day. Similarly for the spent hen study, the temperature and relative humidity data were $24.4^{\circ} \mathrm{C}$ and $87 \%$ on the first replicate day and $27.8^{\circ} \mathrm{C}$ and $29 \%$ on the second replicate day. In Experiment 2, the temperature and relative humidity were $28.9^{\circ} \mathrm{C}$ and $72 \%$, respectively.

\subsection{Serum Corticosterone Concentrations}

All birds subjected to $\mathrm{CO}_{2}$ or foam treatments died. None of the hens (young or spent) survived. The mean serum CORT concentration of young hens subjected to the NEG control, $\mathrm{CO}_{2}$ added to a chamber, $\mathrm{CO}_{2}$ pre-charged chamber, $\mathrm{CAF}$ in cages, and CAF in a chamber treatments were 8.4, 8.0, $4.4,7.0$, and $18.2 \mathrm{ng} / \mathrm{mL}$, respectively (Figure 1). There were no statistically significant differences in serum CORT concentration of young hens subjected to the five treatments $(p=0.569)$. The stress responses of the young hens to gas inhalation and compressed air foam treatments were comparable to the NEG control group. Unlike the young hens, a statistically significant difference was observed in the CORT concentrations of spent hens among the treatment groups $(p=0.0005)$. Birds in the CAF in a chamber group had significantly higher CORT levels than hens in the remaining four treatment groups. The mean serum CORT concentrations of spent hens assigned to CAF in a chamber group was $27.1 \mathrm{ng} / \mathrm{mL}$ while that of the NEG control, $\mathrm{CO}_{2}$ added to a chamber, $\mathrm{CO}_{2}$ pre-charged chamber, and CAF in cages were $5.0,10.3,2.6$, and $8.2 \mathrm{ng} / \mathrm{mL}$, respectively. Though only numerically different, the CORT level of young hens subjected to CAF in a chamber was higher than rest of the four treatments. Yan et al. [42] reported no age-related effects on CORT levels of caged White Leghorn pullets.

Scanes [43] reported that stressors like heat, cold, floor space, restraining, catching, shackling, feed restriction, and nutrient deficiency elevates plasma CORT in poultry. Exposure to $\mathrm{CO}_{2}$ has also been reported to cause pain or distress in animals [44,45]. The results of Experiment 1 demonstrates that the CAF in a chamber method was significantly more stressful to spent hens than the $\mathrm{CO}_{2}$ inhalation, CAF in cages, and NEG control treatments. The chamber was a novel environment to the hens, which might have resulted in higher CORT levels than the CAF in a cage or NEG control treatment. However, the serum CORT levels of young hens as well as spent hens subjected to CAF in cages were similar to the NEG control and $\mathrm{CO}_{2}$ inhalation treatments. Benson and colleagues [1] reported that serum CORT levels of broilers had no statistically significant difference among compressed air foam alone, compressed air foam with $\mathrm{CO}_{2}$, and the $\mathrm{CO}_{2}$ polyethylene tent method. Hens subjected to the pre-charged $\mathrm{CO}_{2}$ chamber had numerically lower CORT levels as compared to the other treatments. It is likely that these hens lost consciousness earlier than hens in other treatments. $\mathrm{CO}_{2}$ reduces the intracellular brain $\mathrm{pH}$, leading to induction of anesthesia [46]. The hens were subjected to higher concentration of $\mathrm{CO}_{2}$ at once in this treatment. 


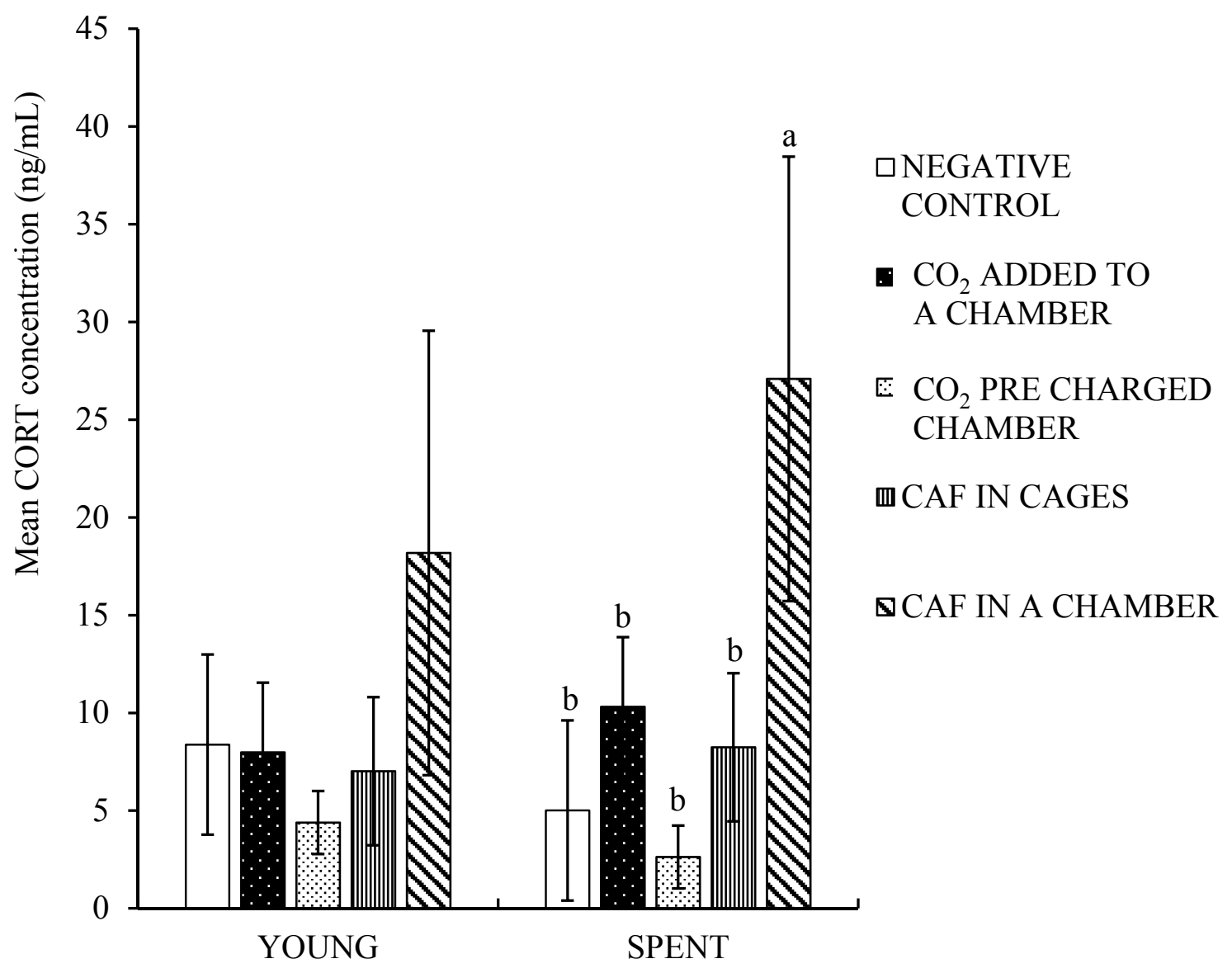

Treatments

Figure 1. Corticosterone concentration of young and spent hens. The corticosterone (CORT) concentrations were measured in duplicates and expressed in $\mathrm{ng} / \mathrm{mL}$. Bars (mean $\pm \mathrm{SEM}$ ) with different superscripts are statistically significantly different by Fisher's LSD test $(p<0.05)$. Young and spent hen trials were conducted separately. Twelve young hens and 13 spent hens were used in each treatment.

\subsection{Time to Cessation of Movement}

Birds undergo terminal convulsive movements after onset of unconsciousness until they become motionless [27]. The termination of clonic and tonic phase of convulsions is known as cessation of movement. The times to $\mathrm{COM}$ (or cessation time) of spent hens subjected to the $\mathrm{CAF}$ in cages, $\mathrm{CO}_{2}$ added to a chamber and aspirated foam in floor pens were determined based on accelerometer readings (Figure 2). The average time to $\mathrm{COM}$ was $90 \mathrm{~s}$ for birds in $\mathrm{CO}_{2}$ in a chamber, $195 \mathrm{~s}$ for birds in CAF in cages, and $192 \mathrm{~s}$ for hens subjected to aspirated foam treatments. A statistically significant difference in mean time to COM was observed among the three treatments $(p<0.05)$. A post hoc Fisher's LSD test revealed that time to cessation of movement of hens subjected to $\mathrm{CO}_{2}$ added to a chamber was significantly shorter than that of hens in the CAF in cages and aspirated foam groups. 


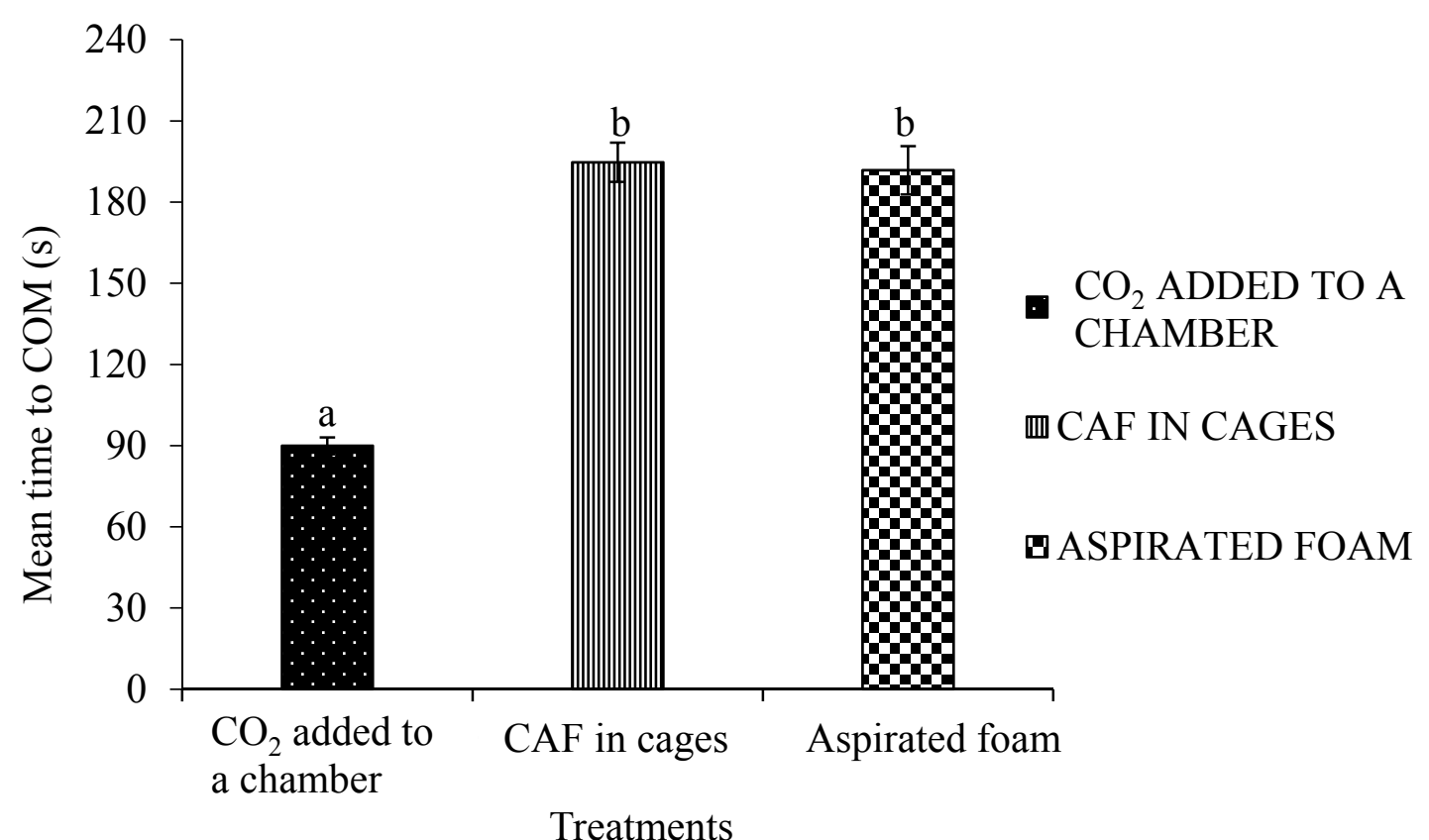

Figure 2. Time to cessation of movement $( \pm S E M)$ of spent hens. Bars (mean $\pm S E M)$ with different superscripts have statistically significant difference by Fisher's LSD test $(p<0.05)$. Sixteen spent hens were randomly assigned to each treatment. The treatments in this trial were carbon dioxide added to a chamber, compressed air foam in cages, and aspirated foam.

In the present study, times to cessation of movement of spent hens assigned to CAF in cages and aspirated foam treatments were within the ranges reported in previous studies. Based on electrocardiography (ECG) readings, Benson et al. [1] reported that time to cessation of cardiac activity of broilers subjected to foam with $\mathrm{CO}_{2}$, foam without $\mathrm{CO}_{2}$, and the polyethylene tent method were $73 \mathrm{~s}$, $64 \mathrm{~s}$, and $139 \mathrm{~s}$, respectively. Dawson et al. [27] reported the time to cessation of movement of broilers subjected to water-based foam to be in range from 25 to $179 \mathrm{~s}$. In this study, spent hens depopulated using $\mathrm{CO}_{2}$ took significantly less time to be motionless than hens subjected to the aspirated foam and CAF in cages. Loss of consciousness is followed by onset of convulsions [7]. A method that results in quicker loss of consciousness might lead to earlier onset of convulsions, resulting in a shorter time to COM. In this study, the hens in the $\mathrm{CO}_{2}$ added to a chamber group had shorter time to $\mathrm{COM}$, which might suggest that those birds lost consciousness earlier than the hens in other treatments. Mean cessation times of spent hens belonging to the CAF in cages and aspirated foam treatments were not significantly different. Wing flapping and struggling of the hens may have agitated the foam bubbles creating air pockets in the foam treatments. The time taken for foam to fill the cages and form a blanket of foam around the birds was longer than filling of the chamber with $\mathrm{CO}_{2}$, which may suggest a second reason for increased cessation times in both of the foam treatments.

\subsection{Gross Necropsy Findings}

Gross necropsy was performed on hens subjected to $\mathrm{CAF}$ and $\mathrm{CO}_{2}$ treatments in Experiment 1. The trachea, syrinx, and bronchi were evaluated for signs of hemorrhage, presence of foam, and presence of blood. Traces of foam were present in the upper trachea (first $5 \mathrm{~cm}$ ) but absent in the lower trachea, syrinx, and bronchi. There were no signs of trauma or injury in the airways of hens since no blood or hemorrhages were found on necropsy. The hens randomly assigned to the $\mathrm{CO}_{2}$ added to a chamber and $\mathrm{CO}_{2}$ pre-charged chamber groups had no signs of hemorrhage or injury to the respiratory tract. Exposure to $\mathrm{CO}_{2}$ treatments resulted in asphyxiation followed by generalized hypoxia and death. The cause of death of all hens subjected to the CAF treatments was due to occlusion of airways by foam leading to hypoxia. Benson et al. [1] reported that broilers subjected to water-based foam died 
due to hypoxia due to occlusion of the trachea. In the same study, Benson and colleagues showed that foam was present in the trachea and lungs of broiler chickens. Blood was found in the syrinx, bronchi, and lungs upon histological examination. Raj et al. [47] conducted a trial to kill end-of-lay hens using a dry nitrogen foam in which they observed foam bubbles around the larynx and upper part of trachea. McKeegan et al. [17] in their study on gas-filled high-expansion foam observed small foam bubbles in trachea and tracheal openings of broilers exposed to high expansion nitrogen foam.

The use of CAF for depopulation does not require manual handling of live birds. Unlike $\mathrm{CO}_{2}$ inhalation, CAF does not present safety risks to the personnel involved. In addition, a CAF can be used as a means for cleaning and disinfection of infected premises after completion of depopulation and disposal of the carcasses [48]. This paper is the first peer-reviewed manuscript on the application of CAF as a means of depopulation of caged layer hens.

\section{Conclusions}

The CORT levels of hens subjected to CAF in cages and the AVMA approved $\mathrm{CO}_{2}$ inhalation treatments were similar to that of birds in the NEG control. The use of $\mathrm{CO}_{2}$ elicited COM earlier than foam-based treatments, possibly due to the anesthetic properties of the gas and differences in filling times of the two methods. The presence of foam in the upper trachea of hens confirms that the cause of death was due to occlusion of the trachea leading up to hypoxia. These findings suggest that the application of compressed air foam in cages may be a viable means for depopulation of caged layer hens during reportable disease outbreaks or natural disasters. Further research needs to be conducted on the addition of carbon dioxide and nitrogen-infused CAF for layer hen depopulation.

Acknowledgments: The authors thank the United States Department of Agriculture-Animal and Plant Health Inspection Service Veterinary Service (VS) for funding this study (Grant number: 08-6100-0035-GR). Technical support was graciously provided by the Texas A\&M Engineering Extension Service, Rowe Industries, and CAFSCO.

Author Contributions: John Hoffman, Kendre Stringfellow, and Morgan Farnell performed the experiments. John Hoffman, Shailesh Gurung, Daad Abi-Ghanem, Luc Berghman, Dan Zhao, and Yuhua Farnell processed the samples. David Caldwell, Darrel Styles, James Byrd, Gregory Archer, and Morgan Farnell conceived and designed the experiments. Jason Lee analyzed the data. Shailesh Gurung and Morgan Farnell wrote the paper.

Conflicts of Interest: The authors declare no conflicts of interest.

\section{References}

1. Benson, E.; Malone, G.W.; Alphin, R.L.; Dawson, M.D.; Pope, C.R.; van Wicklen, G.L. Foam-based mass emergency depopulation of floor-reared meat-type poultry operations. Poult. Sci. 2007, 86, 219-224. [CrossRef] [PubMed]

2. U. S. National List of Reportable Animal Diseases (NLRAD)-National Animal Health Reporting System (NAHRS) Operational Manual. Available online: https:/ /www.aphis.usda.gov/animal_health/nahrs/ downloads/nahrsoperationalmanual.pdf (accessed on 12 September 2017).

3. McCluskey, B.J.; Burgess, B.; Glover, J.; Kinde, H.; Hietala, S. Use of sentinel chickens to evaluate the effectiveness of cleaning and disinfection procedures in noncommercial poultry operations infected with exotic Newcastle disease virus. J. Vet. Diagn. Investig. 2006, 18, 296-299. [CrossRef] [PubMed]

4. Final Report for the 2014-2015 Outbreak of Highly Pathogenic Avian Influenza (HPAI) in the United States. Available online: https://www.aphis.usda.gov/animal_health/emergency_management/downloads/hpai/ 2015-hpai-final-report.pdf (accessed on 12 September 2017).

5. Greene, J.L. Update on the Highly-Pathogenic Avian Influenza Outbreak of 2014-2015. Congressional Research Service, 2015. Available online: https://www.fas.org/sgp/crs/misc/R44114.pdf (accessed on 10 August 2017).

6. Newton, J.; Kuethe, T. Economic Implications of the 2014-2015 Bird Flu. Farmdoc Dly. 2015, 5, 104. Available online: http:/ / farmdocdaily.illinois.edu/2015/06/economic-implications-of-the-2014-2015-birdflu.html (accessed on 10 August 2017). 
7. AVMA Guidelines for the Euthanasia of Animals: 2013 Edition. Available online: https://www.avma.org/ KB/Policies/Documents/euthanasia.pdf (accessed on 10 August 2017).

8. Poultry Depopulation. Available online: https://www.avma.org/KB/Policies/Pages/Poultry-Depopulation. aspx (accessed on 12 August 2017).

9. HPAI Outbreak 2014-2015 Stamping-Out \& Depopulation Policy. Available online: https://www.aphis. usda.gov/animal_health/emergency_management/downloads/hpai/depopulationpolicy.pdf (accessed on 15 August 2017).

10. Highly Pathogenic Avian Influenza Response Plan: The RedBook. Available online: https://www. aphis.usda.gov/animal_health/emergency_management/downloads/hpai_response_plan.pdf (accessed on 15 August 2017).

11. Lambooij, E.; Gerritzen, M.A.; Engel, B.; Hillebrand, S.J.W.; Lankhaar, J.; Pieterse, C. Behavioural responses during exposure of broiler chickens to different gas mixtures. Appl. Anim. Behav. Sci. 1999, 62, 255-265. [CrossRef]

12. Otsuguro, K.; Yasutake, S.; Yamaji, Y.; Ban, M.; Ohta, T.; Ito, S. Why does carbon dioxide produce analgesia? In Alternatives to Animal Testing and Experimentation Journal, Proceedings of the 6th World Congress on Alternatives \& Animal Use in the Life Sciences, Tokyo, Japan, 21-25 August 2007; Japanese Society for Alternatives to Animal Experiments: Tokyo, Japan, 2008; Volume 14, pp. 101-106.

13. Gerritzen, M.A.; Lambooij, E.; Reimert, H.G.M.; Spruijt, B.M.; Stegeman, J.A. Susceptibility of duck and turkey to severe hypercapnic hypoxia. Poult. Sci. 2006, 85, 1055-1061. [CrossRef] [PubMed]

14. McKeegan, D.E.F.; McIntyre, J.; Demmers, T.G.M.; Wathes, C.M.; Jones, R.B. Behavioural responses of broiler chickens during acute exposure to gaseous stimulation. Appl. Anim. Behav. Sci. 2006, 99, 271-286. [CrossRef]

15. Anton, F.; Euchner, I.; Handwerker, H.O. Psychophysical examination of pain induced by defined CO, pulses applied to the nasal mucosa. Pain 1992, 49, 53-60. [CrossRef]

16. Lucke, J.N. Euthanasia in small animals. Vet. Rec. 1979, 104, 316-318. [CrossRef] [PubMed]

17. McKeegan, D.E.F.; Reimert, H.G.M.; Hindle, V.A.; Boulcott, P.; Sparrey, J.M.; Wathes, C.M.; Demmers, T.G.M.; Gerritzen, M.A. Physiological and behavioral responses of poultry exposed to gas-filled high expansion foam. Poult. Sci. 2013, 92, 1145-1154. [CrossRef] [PubMed]

18. McKeegan, D.E.F.; Sparks, N.H.C.; Sandilands, V.; Demmers, T.G.M.; Boulcott, P.; Wathes, C.M. Physiological responses of laying hens during whole-house killing with carbon dioxide. Br. Poult. Sci. 2011, 52, 645-657. [CrossRef] [PubMed]

19. Benson, E.R.; Alphin, R.L.; Dawson, M.D.; Malone, G.W. Use of water-based foam to depopulate ducks and other species. Poult. Sci. 2009, 88, 904-910. [CrossRef] [PubMed]

20. Malone, B.; Benson, E.; Alphin, B.; Van Wicklen, G.; Pope, C. Methods of Mass Depopulation for Poultry Flocks with Highly Infectious Disease. In Proceedings of the ANECA Symposium on Emerging Diseases, Queretaro, Mexico, November 2007.

21. Rie, D.-H.; Lee, J.-W.; Kim, S. Class B fire-extinguishing performance evaluation of a compressed air foam system at different air-to-aqueous foam solution mixing ratios. Appl. Sci. 2016, 6, 191. [CrossRef]

22. Scheffey, J.L.; Darwin, R.L.; Leonard, J.T. Evaluating firefighting foams for aviation fire protection. Fire Technol. 1995, 31, 224-243. [CrossRef]

23. Magrabi, S.A.; Dlugogorski, B.Z.; Jameson, G.J. A comparative study of drainage characteristics in AFFF and FFFP compressed-air fire-fighting foams. Fire Saf. J. 2002, 37, 21-52. [CrossRef]

24. Benson, E.R.; Alphin, R.L.; Rankin, M.K.; Caputo, M.P.; Hougentogler, D.P.; Johnson, A.L. Mass Emergency Water-Based Foam Depopulation of Poultry. Avian Dis. 2012, 56, 891-896. [CrossRef] [PubMed]

25. Alphin, R.L.; Benson, E.R.; Hougentogler, D.P.; Herrman, E.R. Is foam an option for addressing the challenges associated with the depopulation of caged layers? In Proceedings of the 5th International Symposium Managing Animal Mortalities, Products, By-Products, \& Associated Heath Risks: Connecting Research, Regulations, \& Responses, Lancaster, PA, USA, 28 September-1 October 2015.

26. Raj, A.B.M.; Wotton, S.B.; Gregory, N.G. Changes in the somatosensory evoked potentials and spontaneous electroencephalogram of hens during stunning with a carbon dioxide and argon mixture. Br. Vet. J. 1992, 148, 147-156. [CrossRef]

27. Dawson, M.D.; Lombardi, M.E.; Benson, E.R.; Alphin, R.L.; Malone, G.W. Using accelerometers to determine the cessation of activity of broilers. J. Appl. Poult. Res. 2007, 16, 583-591. [CrossRef] 
28. Erasmus, M.A.; Turner, P.V.; Widowski, T.M. Measures of insensibility used to determine effective stunning and killing of poultry. J. Appl. Poult. Res. 2010, 19, 288-298. [CrossRef]

29. Brown, D.D.; Kays, R.; Wikelski, M.; Wilson, R.; Klimley, A.P. Observing the unwatchable through acceleration logging of animal behavior. Anim. Biotelem. 2013, 1, 1-16. [CrossRef]

30. Dawson, M.D.; Johnson, K.J.; Benson, E.R.; Alphin, R.L.; Seta, S.; Malone, G.W. Determining cessation of brain activity during depopulation or euthanasia of broilers using accelerometers. J. Appl. Poult. Res. 2009, 18, 135-142. [CrossRef]

31. Matteri, R.L.; Carroll, J.A.; Dyer, C.J. Neuroendocrine responses to stress. In The Biology of Animal Stress: Basic Principles and Implications for Animal Welfare, 1st ed.; Moberg, G.P., Mench, J.A., Eds.; CABI Publishing: New York, NY, USA, 2000; pp. 43-76. ISBN 0851993591.

32. Post, J.; Rebel, J.; ter Huurne, A. Physiological Effects of Elevated Plasma Corticosterone Concentrations in Broiler Chickens. An Alternative Means by Which to Assess the Physiological Effects of Stress. Poult. Sci. 2003, 82, 1313-1318. [CrossRef] [PubMed]

33. Smith, S.M.; Vale, W.W. The role of the hypothalamic-pituitary-adrenal axis in neuroendocrine responses to stress. Dialogues Clin. Neurosci. 2006, 8, 383-395. [PubMed]

34. Siegel, H.S. Physiological stress in birds. BioScience 1980, 30, 529-534. [CrossRef]

35. Davis, G.S.; Siopes, T.D. Relationship between plasma corticosterone levels and poult mortality and the effects of feeding corticosterone on poult performance. Poult. Sci. 1989, 68, 880-884. [CrossRef] [PubMed]

36. Laundess, A.J.; Rayson, M.S.; Dlugogorski, B.Z.; Kennedy, E.M. Small-scale test protocol for firefighting foams DEF(AUST)5706: Effect of bubble size distribution and expansion ratio. Fire Technol. 2011, 47, 149-162. [CrossRef]

37. A Firefighter's Guide to Foam. 2013. Available online: http:/ / foamtechnology.us/Firefighters.pdf (accessed on 15 December 2017).

38. Bedanova, I.; Voslarova, E.; Chloupek, P.; Pistekova, V.; Suchy, P.; Blahova, J.; Dobsikova, R.; Vecerek, V. Stress in broilers resulting from shackling. Poult. Sci. 2007, 86, 1065-1069. [CrossRef] [PubMed]

39. Olanrewaju, H.A.; Purswell, J.L.; Collier, S.D.; Branton, S.L. Effects of genetic strain and light intensity on blood physiological variables of broilers grown to heavy weights. Poult. Sci. 2013, 92, 1029-1039. [CrossRef] [PubMed]

40. Zhang, J.P.; Delichatsios, M.; Neill, A.O. Assessment of gas cooling capabilities of compressed air foam systems in fuel-and ventilation-controlled compartment fires. J. Fire Sci. 2011, 29, 543-554. [CrossRef]

41. Kim, A.K.; Dlugogorski, B.Z. Multipurpose overhead compressed-air foam system and its fire suppression performance. J. Fire Prot. Eng. 1996, 8, 133-150. [CrossRef]

42. Yan, F.F.; Hester, P.Y.; Enneking, S.A.; Cheng, H.W. Effects of perch access and age on physiological measures of stress in caged White Leghorn pullets. Poult. Sci. 2013, 92, 2853-2859. [CrossRef] [PubMed]

43. Scanes, C.G. Biology of stress in poultry with emphasis on glucocorticoids and the heterophil to lymphocyte ratio. Poult. Sci. 2016, 95, 2208-2215. [CrossRef] [PubMed]

44. Martoft, L.; Lomholt, L.; Kolthoff, C.; Rodriguez, B.E.; Jensen, E.W.; Jørgensen, P.F.; Pedersen, H.D.; Forslid, A. Effects of $\mathrm{CO}_{2}$ anaesthesia on central nervous system activity in swine. Lab. Anim. 2002, 36, 115-126. [CrossRef] [PubMed]

45. Conlee, K.M.; Stephens, M.L.; Rowan, A.N.; King, L.A. Carbon dioxide for euthanasia: Concerns regarding pain and distress, with special reference to mice and rats. Lab. Anim. 2005, 39, 137-161. [CrossRef] [PubMed]

46. Martoft, L.; Stødkilde-Jørgensen, H.; Forslid, A.; Pedersen, H.D.; Jørgensen, P.F. $\mathrm{CO}_{2}$ induced acute respiratory acidosis and brain tissue intracellular $\mathrm{pH}$ : A 31P NMR study in swine. Lab. Anim. 2003, 37, 241-248. [CrossRef] [PubMed]

47. Raj, A.; Smith, C.; Hickman, G. Novel method for killing poultry in houses with dry foam created using nitrogen. Vet. Rec. 2008, 162, 722-723.

48. Hinojosa, C.A.; Caldwell, D.J.; Byrd, J.A.; Ross, M.A.; Stringfellow, K.D.; Fowlkes, E.J.; Lee, J.T.; Stayer, P.A.; Farnell, Y.Z.; Farnell, M.B. Use of a foaming disinfectant and cleaner to reduce aerobic bacteria on poultry transport coops. J. Appl. Poult. Res. 2015, 24, 364-370. [CrossRef]

(C) 2018 by the authors. Licensee MDPI, Basel, Switzerland. This article is an open access article distributed under the terms and conditions of the Creative Commons Attribution (CC BY) license (http:/ / creativecommons.org/licenses/by/4.0/). 